\title{
MANUEL GARCÍA-PELAYO Y LA EMERGENCIA DEL IUS COMMUNE EUROPEO
}

LUIS JIMENA QUESADA 
SUMARIO

I. INTRODUCCIÓN: EL PERFIL EUROPEÍSTA DE GARCÍA PELAYO. II. ACERCA DE SU PREOCUPACIÓN POR LA EUROPA DE LOS DERECHOS HUMANOS. III. SU APROXIMACIÓN A LA EUROPA DE LAS INSTITUCIONES. IV. REFLEXIÓN FINAL: SU LEGADO AL DERECHO CONSTITUCIONAL COMÚN EUROPEO. 


\title{
MANUEL GARCÍA-PELAYO Y LA EMERGENCIA DEL IUS COMMUNE EUROPEO
}

POR

\author{
LUIS JIMENA QUESADA*
}

\section{INTRODUCCIÓN: EL PERFIL EUROPEÍSTA DE GARCÍA PELAYO}

De entrada, parece pertinente observar que, por el tiempo que le tocó vivir (1909-1991) y por la propia incorporación tardía de España a las instituciones europeas (con la ratificación en 1979 y 1980 de los dos instrumentos básicos de derechos humanos del Consejo de Europa - el Convenio Europeo de Derechos Humanos y la Carta Social Europea, respectivamente-, y con la adhesión en 1986 a las Comunidades Europeas), el perfil europeísta del Maestro García Pelayo se asocia habitualmente con su obra clásica Derecho constitucional comparado ${ }^{1}$, incidiéndose pues más en la influencia que sobre él ejerció el método europeo horizontal que el método europeo vertical. Sin embargo, ambos métodos

* Profesor de Derecho constitucional en la Universitat de València (España). El autor desea hacer constar que el presente trabajo se ha elaborado en el marco del Proyecto I+D «Europa ante el desafío de la armonización del derecho procesal» (referencia: DER2008/04639), cuya investigadora principal es la Profesora Pía Calderón Cuadrado.

${ }_{1}$ GARCÍA PELAYO, M.: Derecho constitucional comparado, Madrid, Revista de Occidente, 1950 (también en sus Obras Completas, Madrid, CEC, 1991, tomo I, pp. 223-734).

2 Para una explicación de estos dos métodos, léase CONSTANTINESCO, V.: “¿Hacia la emergencia de un Derecho constitucional europeo?», Cuadernos Constitucionales de la Cátedra Fadrique Furió Ceriol, no 8, 1994, p. 9: «El primero, es el tema 'horizontal': ¿¿de la confrontación y de la comparación entre las constituciones europeas - iy ahora no se trata solamente de una docena de constituciones, sino de una treintena!- - puede nacer un modelo constitucional europeo? El segundo, es el tema 'vertical': un cierto número de instrumentos internacionales y de organizaciones 
van de la mano, como lo prueba el peso que se confiere a la idea de tradiciones constitucionales comunes a los Estados miembros en el seno de la Unión Europea.

Así, en su "Autobiografía intelectual», el propio García Pelayo pone de manifiesto su vocación europeísta, tanto al completar su formación jurídico-filosófica con el acercamiento a autores españoles de proyección continental, como al potenciar eso que hoy damos en llamar «movilidad» en el Espacio Europeo de Educación Superior: en cuanto a lo primero, recuerda García Pelayo que en los últimos años de su carrera decidió intensificar sus «estudios en filosofía del Derecho recibiendo para ello la benévola acogida de don Luis Recasens Siches, quien había puesto los estudios filosófico-jurídicos 'a nivel europeo', como se diría ahora ${ }^{3}$, añadiendo que ejerció sobre él, al igual que sobre la mayoría de su generación, «un gran influjo la obra de Ortega»" En lo que atañe a lo segundo, trae a colación García Pelayo su traslado a Viena en 1934 «pensionado por la Junta de Ampliación de Estudios», de modo que tuvo ocasión de analizar críticamente la teoría kelseniana y los escritos de Carl Schmitt ${ }^{5}$, y más tarde marchó a Berlín un corto período en 1936, en vísperas de la Guerra Civil española, con objeto de preparar una «lección magistral para unas oposiciones que debían celebrarse en otoño de $1936 »^{6}$.

De tal suerte, García Pelayo fue un testigo privilegiado de los desgraciados acontecimientos que se estaban fraguando en el continente europeo durante el período de entreguerras ${ }^{7}$, tanto de la fraticida contienda española de 1936-

internacionales desarrollan, en su crecimiento, influencias (que a veces se convierten en interacciones) sobre las constituciones nacionales hasta el punto de querer rivalizar con ellas poniendo término a lo que podría denominarse la exclusividad constitucional de los Estados». Léase asimismo la reflexión de ROLDÁN BARBERO, J.: "Democracia y Derecho europeo», Revista de Instituciones Europeas, vol. 20, no 1, enero-abril 1993, p. 101: dicho autor analiza en qué medida un régimen político democrático es un valor tutelado por el «Derecho europeo» que, en su opinión, «desborda el marco comunitario».

3 GARCÍA PELAYO, M.: «Autobiografía intelectual», Obras Completas, tomo I, p. 5.

${ }_{4}$ Ibidem. En estas coordenadas, no es impertinente traer a la memoria cómo J. ORTEGA Y GASSET, en el «Prólogo para franceses» de La rebelión de las masas (1937), llegó a «insinuar que los pueblos europeos son desde hace mucho tiempo una sociedad, una colectividad, en el mismo sentido que tienen estas palabras aplicadas a cada una de las naciones que integran aquélla. (...) hay costumbres europeas, usos europeos, opinión pública europea, Derecho europeo, poder público europeo. Pero todos estos fenómenos se dan en la forma adecuada al estado de evolución en que se encuentra la sociedad europea, que no es, claro está, tan avanzado como el de sus miembros componentes, las naciones».

5 Ibidem, pp. 6-8.

${ }^{6}$ Ibidem, p. 9.

7 Ibidem, p. 5: "percibía que algo había entrado en crisis y desde 1931 comencé a interesarme por las nuevas tendencias políticas que acusaban su presencia en el horizonte europeo. Estudié 
1939 como de esa especie de guerra civil europea que fue la Segunda Guerra Mundial de 1939-1944, la cual condujo a poner las bases del Estatuto del Consejo de Europa en 1949 (con la rápida aprobación, bajo el lema "plus jamais»/ «never more», del Convenio de Roma de 1950 como antídoto contra el totalitarismo) y del Tratado CECA en 1951 (catalogado en parte como tratado de paz franco-alemán). Él resume aquel período reseñando que «la realidad se me revelaba como un gigantesco sistema de contradicciones donde la única política posible parecía ser la Realpolitik, lo que, a medida que avanzaba la guerra mundial, me permitió tener cada vez más esperanzas en la victoria aliada, pero cada vez menos en que esta victoria supusiera la caída del régimen franquista. En todo caso, me sentía joven y fuerte y sólo externa y circunstancialmente vencido» ${ }^{8}$.

Ese perfil europeísta de García Pelayo se inscribe en una más amplia proyección internacional, con una fructífera movilidad universitaria durante su «época suramericana», que comenzó en 1951 y duraría aproximadamente treinta años: de ese extenso período trae al recuerdo cómo en 1954, en la Universidad de Rio Piedras (en Puerto Rico), percibió la idea de Universidad como universitas, pues «además de los profesores puertorriqueños, la Universidad contaba entonces con un gran número de docentes extranjeros de varias nacionalidades americanas y europeas». Durante ese período en Latinoamérica, no obstante, no dejó de prestar atención a la situación política en Europa; de hecho, trae a la memoria «en el ámbito de mis preocupaciones en la década de los años cincuenta (...) la sedimentación de las experiencias el mundo político que me había tocado vivir y a las que he hecho referencia al ocuparme de la época de la guerra civil y de la guerra mundial» ${ }^{9}$; todo lo cual muestra el intéres y la aportación de nuestro autor por un período clave para la comprensión de la emergencia del ius commune europeo de nuestros días.

Dicho lo cual, esa percepción europeísta se prolongó a lo largo de la vida de García Pelayo, quien siguió observando el imperativo de una transnacionalidad europea en el marco del «Estado internacionalmente integrado» ${ }^{10}$. En palabras

algunas obras de Marx, del Marx maduro, único que entraba entonces en nuestro horizonte; leí a Trotski, a Lenin y a otros bolcheviques como Bujarin, Zinóviev y Radek, cuyas obras (especialmente de los dos últimos) desaparecieron más tarde de la circulación, y no dejé, en fin, de mostrar interés, que satisfacía en la medida de lo posible, por el fascismo italiano, asomándome a los escritos de Gentile, Panunzio y Rocco».

8 Ibidem, p. 10.

9 Ibidem, p. 12.

10 Sobre el alcance de esta expresión, léase TORRES DEL MORAL, A.: «El Estado internacionalmente integrado», en Estado de Derecho y democracia de partidos, Madrid, Universidad Complutense, 2004, 2a ed., pp. 109 y ss. 
suyas, «el desarrollo de la sociedad organizacional rebasa las fronteras de cada país dando origen a la sociedad transnacional $»^{11}$.

\section{ACERCA DE SU PREOCUPACIÓN POR LA EUROPA DE LOS DERECHOS HUMANOS}

Los impresionantes conocimientos de historia y pensamiento políticos del Profesor García Pelayo vuelven a facilitarnos la comprensión sobre la construcción continental tras la segunda contienda mundial como fenómeno asociado implícitamente a una preocupación por la Europa de los derechos humanos, en la medida en que - como anteriormente se ha apuntado por referencia a la creación del Consejo de Europa y de la primera Comunidad europea, la CECA - se trataba de conjurar el peligro para el futuro de nuevos brotes de totalitarismo $\mathrm{y}$, por tanto, de colocar sobre bases sólidas una paz duradera basada en la democracia y el Estado de Derecho.

En esta línea, se puede establecer un claro paralelismo entre la pérdida de hegemonía como potencia mundial del Reino Unido tras la Segunda Guerra Mundial y ese mismo declive del continente europeo en el contexto mundial. Efectivamente, en su obra sobre El imperio británico García Pelayo da buena cuenta de esa menor preponderancia del Reino Unido ${ }^{12}$, que discurrió por el

${ }^{11}$ GARCÍA PELAYO, M.: «Autobiografía intelectual», ya cit., p. 15-17: Y prosigue: esa sociedad transnacional «no [está] constituida por las relaciones entre Estados (como la llamada convencionalmente sociedad internacional), sino entre actores sociales pertenecientes a distintos Estados y sociedades nacionales y que, al condicionar las posibilidades de acción de los Estados, han dado lugar a la política transnacional como algo distinto de la política nacional y de la política transnacional. (...) Resultado de la ocupación con todos estos temas fue mi libro sobre Las transformaciones del Estado contemporáneo» (Madrid, Alianza Editorial, 1974; en sus Obras Completas, tomo II, pp. 1585-1758).

12 GARCÍA PELAYO, M.: El imperio británico, Madrid, Revista de Occidente, 1945; en sus Obras Completas, tomo I, pp. 19-222; en concreto, pp. 212-213: «es claro que esta situación de poderío de Gran Bretaña ha cambiado actualmente, y que esta circunstancia sitúa al Imperio ante nuevos problemas. Dicho cambio de situación se manifiesta en tres aspectos: primero: la disminución sufrida por Gran Bretaña en calidad de potencia mundial; es decir, que si bien el Reino Unido es en sí ahora más fuerte que lo era, por ejemplo, hace treinta años, no posee en cambio el mismo coeficiente de poder mundial; segundo: durante el pasado siglo, y en realidad hasta la presente guerra, era la única potencia mundial efectiva y el único poder que verdaderamente desarrollaba una Weltpolitik; pero hoy, después, de una guerra con un teatro y unos fines literalmente mundiales, en la que no ha sido dirigente, sino coparticipante, y cuando tres hombres se reúnen para decidir el orden de todo el planeta, no es necesario esforzarse en demostrar que la situación ha cambiado (...)». 
mismo cauce que la pérdida de protagonismo del continente europeo: tras la guerra, Europa dejó de ser sujeto de la historia para convertirse en objeto de ella.

En cualquier caso, así como en el diseño de la «Europa del mercado común» el Reino Unido ejerció una presión estratégica externa no suscribiendo la Declaración Schuman en 1950 ni los Tratados constitutivos de las tres Comunidades Europeas en 1951-1957 (apartado III, infra), en la previa concepción del Consejo de Europa asumió un protagonismo directo, y no por casualidad el Estatuto fundador de esta organización se firmó en Londres en 1949. Lógicamente, la posición británica se mostró proclive a compartir un proyecto en el seno de una organización internacional clásica de cooperación (el Consejo de Europa) y, en cambio, reticente a la hora de unirse a una organización europea de integración (las Comunidades Europeas).

De todos modos, en la dinámica de la Europa de los derechos humanos los teóricos roles asignados a cada organización en ocasiones parecen haber ido invirtiéndose. El caso es que, en efecto, en el Consejo de Europa, su instrumento más emblemático (el Convenio Europeo de Derechos Humanos) ha generado una jurisprudencia (la del Tribunal Europeo de Estrasburgo) que ha tenido un relevante impacto constitucional (incluso en términos de «ataque a la soberanía estatal») en las Partes Contratantes ${ }^{13}$, entre ellas el Reino Unido (que ratificó dicho Convenio en 1951). Diversamente, en el marco de la Unión Europea (en la que los Estados han hecho cesión de «derechos soberanos» a tenor de la clásica jurisprudencia del Tribunal de Justicia de Luxemburgo $^{14}$ ), países como Polonia y el Reino Unido negociaron un Protocolo "peculiar» anejo al Tratado de Lisboa de 2007 sobre la aplicación de la Carta de los derechos fundamentales.

Volviendo a la posición británica con relación a la Europa de los derechos humanos, es verdad que a pesar de la ratificación por parte del Reino Unido del Convenio Europeo de Derechos Humanos en 1951, en las islas el texto convencional había venido teniendo un controvertido estatuto particular, que precisó reformularse en clave de suscripción sin reservas del ius commune europeo en 1998, mediante la Human Rights Act ${ }^{15}$. Ese gesto de alinearse con la cultura eu-

${ }_{13}$ Puede acudirse a JIMENA QUESADA, L.: Sistema europeo de derechos fundamentales, Madrid, Colex, 2006, en particular el epígrafe II (»La jurisprudencia del Tribunal y el orden constitucional de las Partes Contratantes») del capítulo tercero [»La obra del Consejo de Europa (II): el Convenio Europeo de Derechos Humanos (Segunda Parte)»].

${ }^{14}$ Sentencia de 5 de febrero de 1963 dictada en el caso Van Gend \& Loos.

15 Esta Ley, mediante la que se incorpora el Convenio Europeo de Derechos Humanos, tuvo la sanción real (Royal assent) el 9 de noviembre de 1998, entrando en vigor el 2 de octubre de 2002. A este respecto, en la guía preparada al efecto por el Ministerio del Interior británico 
ropea de los derechos y libertades no debe extrañar, por el correlativo bagaje que nos ha legado históricamente el Reino Unido pues, como advirtió García Pelayo, «no hay constitución que haya tenido una influencia tan grande en la formación del Derecho constitucional liberal como la Constitución británica, y ello tanto en el aspecto del Derecho positivo como en el de la teoría y de la técnica jurídico-constitucional. (...) el sistema británico inspira todo el llamado 'constitucionalismo' europeo» ${ }^{16}$.

Por lo demás, es evidente que el parámetro del Convenio de Roma de 1950 y sus Protocolos se configura como ineludible en la emergencia y consolidación del ius commune europeo ${ }^{17}$ : con tal espíritu, la ya desaparecida Comisión Europea de Derechos Humanos afirmó que «como el Convenio (Europeo de Derechos Humanos) refleja el orden público europeo, la Comisión puede acudir, para interpretarlo, a la larga experiencia de algunos Estados miembros» ${ }^{18}$.

De tal parámetro se hizo eco García Pelayo, como no podía ser de otro modo por imperativo de nuestra Norma Suprema, en su época de Magistrado y Presidente del Tribunal Constitucional. Cabalmente, en dicha época —de an-

(Home Office) para dar a conocer el Convenio Europeo a todos los funcionarios públicos a través de dicha Ley (guía bajo el título «A New Era of Rights and Responsibilities - Core Guidance for Public Authorities» a la que se puede acceder a través del sitio web www.homeoffice.gov.uk/hract) pueden leerse las palabras del Ministro del Interior a la sazón (Mike O’Brien), para quien la Human Rights Act «establece nuevas responsabilidades para todos aquellos que trabajan en el sector público. Tenemos atribuida una función vital en la creación de una nueva cultura de los derechos humanos. Espero que esta Core Guidance sea una valioso instrumento para hacer realidad esa nueva cultura».

${ }^{16}$ GARCÍA PELAYO, M.: Derecho constitucional comparado, op. cit., pp. 462-463.

17 Así lo ha expresado DE SALVIA, M.: «L'élaboration d'un ius commune des droits de l'homme et des libertés fondamentales dans la perspective de l'unité européenne: l'oeuvre accomplie par la Commission et la Cour européennes des Droits de l'Homme», en el colectivo Studies in honour oflMélanges en honneur de Gérard J. Wiarda, Strasbourg, Carl Heymanns Verlag KG, 1988, en especial, p. 556: «el ius commune no se presta a definiciones concretas. (...) Por tanto, el ius commune sólo puede resultar de un conjunto de principios derivados de la jurisprudencia de los órganos del Convenio: el principio del respeto de la dignidad de la persona humana; el principio de legalidad; el principio de la igualdad de armas en el proceso; el principio de proporcionalidad. Ciertamente, esta lista no es exhaustiva; podrían añadirse otros principios. Sin embargo, es sobre todo a través de estos principios como se elaborará un ius commune de los derechos fundamentales». Con una afirmación más genérica, pero con análoga orientación, ha observado SUDRE, F.: La Convention européenne des droits de l'homme, París, PUF (Collection «Que sais-je?»), no 2513, 1992, 2a ed., p. 75: «el TEDH da lugar a un Derecho común europeo de los derechos y libertades, que es la traducción del 'patrimonio común' evocado en el Preámbulo del CEDH».

${ }_{18}$ Informe de la Comisión en el caso Campbell y Cosans contra el Reino Unido, Serie B, Vol. 42, 1980-1983, p. 46, parágrafo 61, Estrasburgo, 1985. 
dadura inicial de nuestro Alto Tribunal-, unas cuantas sentencias constitucionales en las que intervino García Pelayo trazaron las líneas básicas para un correcto encuadre del Convenio Europeo de Derechos Humanos en nuestro marco constitucional ${ }^{19}$, sobre todo merced al claro mandato interpretativo del artículo 10.2 de nuestro texto constitucional de $1978^{20}$; una corrección y una claridad, dicho sea de paso, que no han encontrado siempre el mismo eco en nuestra jurisprudencia constitucional más reciente (apartado IV, infra).

$\mathrm{Si}$ acaso, y este es un dato que lamentablemente no cabe silenciar, esos albores brillantes de nuestra jurisdicción constitucional con García Pelayo al frente se vieron oscurecidos con el episodio de la llamada "expropiación de Rumasa». En efecto, la regla general de una incontrovertida y correcta aplicación en nuestro sistema constitucional del estándar europeo en materia de derechos funda-

19 Entre esos pronunciamientos «europeizantes» de la época de García Pelayo en el Tribunal Constitucional merecen destacarse las SSTC 12/1981, de 10 de abril, 25/1981, de 14 de julio, 41/1982, de 2 de julio, y 65/1982 de 10 de noviembre.

${ }^{20}$ Sobre el particular, ha apuntado GARCÍA DE ENTERRÍA, E.: «Valeur de la jurisprudence de la Cour européenne des Droits de l'Homme en droit espagnol», Protecting Human Rights: The European Dimension/ Protection des droits de l'homme: la dimension européenne, op. cit., p. 222: «el Derecho constitucional español conoce un caso absolutamente singular de valor constitucional directo del Convenio Europeo que resulta del artículo 10.2 de la Constitución de 1978. (...) Con independencia de las razones que llevaran a establecer una cláusula de este tipo, explicable únicamente por circunstancias singulares aparecidas en el momento de la elaboración de la Constitución española, está claro que la misma ha introducido en nuestro sistema constitucional una regla primordial de aplicación. Se habrá observado que los instrumentos internacionales de este tipo se convierten en un criterio para la hermenéutica de la Constitución nacional. El precepto constitucional no prevé su eficacia directa como normas internas (esta eficacia directa viene atribuida únicamente a los tratados que han sido ratificados por España, según otro artículo de la Constitución, el artículo 96), precisión importante en lo que se refiere al único instrumento expresamente mencionado en el artículo 10.2, la Declaración Universal de Derechos Humanos». En esa línea se inscribe la STC 82/1982, de 15 de octubre (siendo Presidente del Tribunal Constitucional Manuel García Pelayo), en donde se afirma (FJ 2): «Para interpretar el mencionado artículo $24 \mathrm{CE}$ a los efectos de concretar el alcance de este derecho, hemos de partir (...) del artículo 10.2 CE. (...) De acuerdo con este precepto, la Constitución se inserta en un contexto internacional en materia de derechos fundamentales y libertades públicas, por lo que hay que interpretar sus normas en esta materia de conformidad con la Declaración Universal de Derechos Humanos y los tratados y acuerdos internacionales sobre la mencionada materia ratificados por España»; y añade el Alto Tribunal: «hemos de acudir al Convenio de Roma de 1950, dado el contenido del artículo 10.2 de nuestra Constitución y la competencia reconocida por España a la Comisión y al Tribunal Europeo de Derechos Humanos».Véase asimismo GARCÍA DE ENTERRÍA, E.: «La Convención Europea de Derechos Humanos, requisito moral y económico para la integración», Foro Internacional, no XXXIII-2, 1993, p. 305: «lo más singular del Convenio es, sin duda, el sistema institucional que ha construido para otorgar una garantía efectiva a su carta de derechos». 
mentales (actuación del Tribunal Constitucional como órgano jurisdiccional), contó con la polémica y contestable excepción (actuacion de aquél como órgano político) de las sentencia constitucional dictada en el "caso Rumasa» ${ }^{21}$, que abocó al Presidente García Pelayo a su desafortunado ejercicio del voto de calidad y a su posterior dimisión ${ }^{22}$. Por añadidura, esa excepción quedó confirmada justamente con el reproche de la sentencia dictada el 23 de junio de 1993 por el Tribunal Europeo de Derechos Humanos en el caso Ruiz Mateos contra España, aunque fuera con apoyo exclusivo en la vulneración del derecho a un proceso equitativo (por el plazo irrazonable que hubo de soportar el demandante ante la justicia española en la sustanciación de su causa), con un pronunciamiento meramente declarativo en el que Tribunal de Estrasburgo no otorgó indemnización por tal concepto y rehuyó igualmente entrar a valorar si había mediado asimismo una violación del derecho de propiedad digna de una compensacion económica que hubiera sido desorbitada.

Al hilo de lo anterior, por último, reviste precisamente interés una contribución (»El saber económico europeo») publicada incluso antes de la puesta en marcha efectiva de las Comunidades Europeas, concretamente en el mismo año de la Declaración Schuman, en donde García Pelayo ya evocó que la Europa de los derechos humanos, en el caso de la Europa comunitaria ha venido asociada a su credo básico de sesgo mercantilista y a la mejora del nivel de vida de la ciudadanía consignada en los Preámbulos de los Tratados constitutivos, en ausencia de un catálogo sistemático de derechos y libertades como el que se ha pretendido a través de la introducción de la Carta de los derechos fundamentales de

${ }^{21}$ Véanse sobre este caso, la STC 111/1983, así como las SSTC 166/1986, 67/1988, y 6/1991. En la doctrina española se ha catalogado el "caso Rumasa» como supuesto de "quebrantamiento constitucional» (como «violación ocasional de la Constitución, sin alterar formalmente su vigencia para los demás casos y para el futuro»): así, TORRES DEL MORAL, A.: Estado de Derecho y democracia de partidos, op. cit., pp. 187-188: «el decreto-ley de expropiación del grupo de empresas 'Rumasa', cuando el artículo 86 prohíbe a este tipo de normas afectar a los derechos y libertades regulados en el Título de la Constitución». Así pues, como se indicaba, semejante práctica constituye una excepción, y así lo ha recordado el Profesor Torres del Moral (ibidem, p. 156) por referencia a Manuel García Pelayo: "Como dice García Pelayo, si bien el Derecho constitucional es inconcebible sin el poder, éste sólo adquiere sentido estatal por su vinculación al Derecho. De ahí la importancia del estudio de las fuentes del Derecho constitucional, esto es, de los tipos de normación jurídica que integran la Constitución formal».

${ }^{22}$ Puede leerse «García Pelayo abandonará el Tribunal Constitucional en febrero, coincidiendo con la renovación de cinco magistrados», El Pais, 7 de enero de 1986 [http://www.elpais.com/articulo/espana/GARCiA_PELAYO/_MANUEL/ESPAnA/TRIBUNAL_CONSTITUCIONAL/Garcia/Pelayo/abandonara/Tribunal/Constitucional/febrero/coincidiendo/renovacio n/magistrados/elpepiesp/19860107elpepinac_2/Tes/]. 
la Unión ${ }^{23}$. Al tiempo, sugiere en tal ensayo cómo la fortaleza política de la actual Unión Europea está en directa conexión con el dominio histórico que propicia el mercantilismo ${ }^{24}$. Lo cual nos da pie para adentrarnos en cómo esos planteamientos mercantilistas han moldeado la concepción y evolución de las instituciones europeas.

\section{SU APROXIMACIÓN A LA EUROPA DE LAS INSTITUCIONES}

Aunque García Pelayo no se haya ocupado estrictamente y de manera particularizada de las instituciones europeas (ni del Consejo de Europa ni de la Unión Europea), su obra aporta reflexiones nada desdeñables para comprender con mayor rigor el impacto del engranaje institucional europeo en la vida de las personas. Así, sus estudios arrojan luz en torno a la influencia de la era tecnológica en la concepción de las instituciones comunitarias y en la tecnoburocracia que las gobierna o gestiona, y cómo esa nueva forma de ejercicio del poder da pie para reformular su legitimidad o la idea de soberanía y, sobre todo, para explicar el déficit democrático consistente en el alejamiento de la Europa de las instituciones con respecto a la Europa de la ciudadanialde las personas ${ }^{25}$.

${ }^{23}$ GARCÍA PELAYO, M.: «El saber económico europeo», Revista de Estudios Politicos, no 52, 1950, pp. 175-180; en sus Obras Completas, tomo III, pp. 2379-2385; en especial, p. 2381: «el pensamiento económico es una genuina expresión del modo de ser y de saber europeos, pues se trata de un saber destinado a comprender y a dominar el mundo exterior en su doble vertiente de la naturaleza y de la sociedad. (...) la función de poner la naturaleza al servicio del hombre, ha correspondido siempre a la economía. Por eso si bien los pueblos extraeuropeos, como los chinos o los árabes, han sido autores de invenciones técnicas, sólo el sentido y el saber económico de los pueblos europeos han sido capaces de desplegar de modo amplio esas posibilidades, incorporándolas a la vida diaria de la gran masa de los hombres, ampliar el círculo de apropiación de bienes materiales y culturales, elevando su nivel de vida, y —al impulso de motivos económicos- darles todo el desarrollo que estaba potencialmente contenido en ellas».

24 Ibidem: «Dentro de la época en que Europa aparece como unidad histórica, el primer medio para la dominación de la sociedad por el hombre ha sido el Estado moderno, y justamente con él nace la primera forma de saber económico semicientífico: el mercantilismo».

25 En su «Autobiografía intelectual» (Obras Completas, tomo I, p. 15) indica García Pelayo que se ocupó «de la significación de la tecnología como sustento del poder y, por tanto, de las diferencias de potencial entre los Estados; de su importancia para el nacimiento de la nueva especie de legitimidad funcional y quizá también nuevas formulaciones del concepto y modalidades de la soberanía; de la generación de nuevas formas de gestión estatal, entre las que destaca la tecnocrática; de la interacción entre el Estado y el desarrollo tecnológico, y formulé, en fin, unos modelos tipológicos de Estado basados en la distinta combinación del momento teconológico con otros momentos configuradores del orden político. En resumen, traté de determinar el impacto de la ci- 
Otro elemento de reflexión nada despreciable que nos ha regalado Gacía Pelayo tiene que ver con el entendimiento del juego del poder político en la dinámica de las negociaciones en el ámbito de la Unión Europea. Así, una vez más, de su libro sobre El imperio británico se desprende el modo en que se acometió la propia construcción europea tras la Segunda Guerra Mundial: con sus explicaciones, en particular, llega a comprenderse la paradoja consistente en que, a título de ejemplo, fuera desde el Reino Unido desde donde se lanzara la idea de «Los Estados Unidos de Europa» (el famoso discurso de Winston Churchill en la Universidad de Zurich en 1946) ${ }^{26}$, pero más bien en clave de alentar a unirse a los demás países europeos y los ingleses permanecer estratégicamente al margen del proyecto europeo ${ }^{27}$. De hecho, no resulta extraño:

vilización tecnológica en la estructura, función y posición del Estado». De manera más exhaustiva, en su libro Burocracia y tecnocracia y otros escritos (Madrid, Alianza Editorial, 1974), García Pelayo se refiere a la EURATOM como ejemplo de organización que conoce el impacto de la tecnología en las relaciones interestatales (en sus Obras Completas, tomo II, pp. 1422-1423), así como a la crítica «a la burocracia por su pedantería, por su Kretinismus (...), por su arbitrariedad, por su anonimato y por su irresponsabilidad. Pero todos estos reproches se pueden hacer con mucha más razón a la tecnocracia» (ibidem, pp. 1462-1461); ¿acaso suena esto último lejano al «despotismo ilustrado" de la tecnoburocracia asentada en Bruselas?

26 Speech by Winston Churchill, 19 September 1946, University of Zurich, Switzerland [http://www.coe.int/T/E/Com/About_Coe/DiscoursChurchill.asp]: "What is this sovereign remedy? It is to recreate the European fabric, or as much of it at we can, and to provide it with a structure under which it can dwell in peace, in safety, and in freedom. We must build a kind of United States of Europe. In this way only will hundreds of millions of toilers be able to regain the simple joys and hopes which make life worth living. The process is simple. All that is needed is the resolve of hundreds of millions of men and women to do right instead of wrong and to gain as their reward blessing instead of cursing».

27 GARCÍA PELAYO, M.: El imperio británico, op. cit., p. 210-211: «En la historia del pensamiento político hay dos concepciones polares sobre el poder: el poder como fin en sí mismo (lo que se ha llamado por unos la 'santificación' y por otros 'la demonización' del poder), o el poder como medio para un objeto - hay también una caricatura del primero: el empleo de una fraseología de poder sin contar con los medios reales de poder. Los ingleses se han mantenido apegados a la segunda tesis: lo que interesa es conducir a los demás a un determinado fin, llevarles a cooperar en una tarea, y el poder, concretamente el poder de dominación, es simplemente un medio, un instrumento al servicio de ese fin, que tiene como función la superación de las resistencias que se opongan al objeto planteado. Por tanto, la intensidad de dominación dependerá de la intensidad de la resistencia, bien sea ésta debida a factores subjetivos, es decir, a motivos de oposición política, bien a factores objetivos, como que el grado de desarrollo cultural de un pueblo no le permita incorporarse por sí mismo a la tarea común. En consecuencia, si la adhesión se logra de una manera espontánea, y si, supuesta ésta, la parte integrante del Imperio puede cumplir por sí misma la misión que le corresponde, es decir, si los fines a que sirven los medios de poder dominante han sido alcanzados, entonces sobran tales medios». 
- por una parte, que el Reino Unido no fuera uno de los seis países fundadores de las Comunidades Europeas; o,

- por otra parte, que promoviera la creación de la EFTA en concurrencia con el «mercado común» europeo ${ }^{28}$.

Más aún, García Pelayo explica magistralmente cómo la dinámica del poder político va de la mano de una cierta concepción del poder económico que, en el caso de los ingleses, vendría a explicar asimismo:

- en primer término, que pese a no ser uno de los seis países originarios de las Comunidades Europeas, el Reino Unido decidiera no quedar descartado del concierto económico y, por ende, adherirse a dichas Comunidades (1973), ponderando que realmente era mejor estar dentro que fuera de la casa común europea;

- en segundo lugar, que el euroescepticismo británico, sobre todo en la negociación de la contribución y reparto de los fondos comunitarios, ha sido una constante en todos los gobiernos del Reino Unido con independencia de su color político, por más que suene como más paradigmática la famosa y lapidaria frase que lanzó en su día Margaret Thatcher: "I want my money back»;

- y, por último, que en la evolución de la Unión Europea, el Reino Unido haya mostrado oposición a la hora de produndizar en la idea de Unión "política» (calificativo éste que rechazó con respecto a la Unión Europea cuando se adoptó el Tratado de Maastricht en 1992), o haya acudido con cierta frecuenta a las "cláusulas de salida o de exclusión» (opting out clauses) en cuestiones económicas, como en su día la no suscripción de la Carta comunitaria de los derechos fundamentales sociales de los trabajadors de 1989, o el Protocolo sobre la Unión Económica y Monetaria anejo al Tratado de Maastricht de 1992 que le permitía no compartir la moneda común (el «euro») y mantener su moneda nacional (la libra esterlina).

${ }^{28}$ Como es sabido, los países fundadores de la Unión Europea fueron Francia, Alemania, Italia, Bélgica, Holanda y Luxemburgo. Sólo en 1973 se adhirió el Reino Unido, acompañado de Irlanda y Dinamarca. Con anterioridad, fue iniciativa británica la creación concurrente en 1959 de una pequeña "zona europea de libre cambio» (EFTA -European Free Trade Association) entre Reino Unido, Noruega, Suecia, Dinamarca, Austria, Portugal, Islandia y Suiza. Realmente, la EFTA fue una réplica al mercado común, pese a que al final todos estos países, a la sazón extracomunitarios, se integraron también en el mercado común junto a los seis fundadores (con la excepción, todavía, de Noruega, Islandia y Suiza). 
Para completar el presente apartado, no es posible dejar de aludir a otra de las aportaciones básicas de García Pelayo para la comprensión del proceso de integración política de la Unión Europea, a saber, su «Ensayo sobre una teoría de los símbolos políticos ${ }^{29}$. En particular, la fragilidad que todavía muestra la Unión como entidad política y, por ende, la debilidad de la acción de sus instituciones, se debe en parte al déficit del proceso integrador en lo que se refiere a la vía «irracional» de asunción de los símbolos políticos comúnmente compar$\operatorname{tidos}^{30}$.

Lo expuesto queda patente si se repara en que el Tratado de Lisboa de 2007, en el «rescate sustancial» que efectuó del Tratado constitucional de $2004^{31}$, no consiguió recuperar los símbolos comunes consignados en éste ${ }^{32}$. Por lo demás, a la lucha ideológica en torno a los símbolos políticos, tal como ha sido expuesta por García Pelayo ${ }^{33}$, tampoco escapan las instituciones europeas en el momento de dar visiblidad a esos símbolos compartidos, ni siquiera al explicar dichos símbolos de manera plausible: esto ocurre en el caso de la bande-

29 GARCÍA PELAYO, M.: Mitos y simbolos politicos, Madrid, Taurus, 1964; en sus Obras Completas, tomo I, pp. 907-1031.

30 Ibidem, p. 989: «Toda unidad política — dándole a este vocablo su sentido más amplio, que enóloga no sólo a los Estados (...) - consiste en un proceso de integración, es decir, de conversión de una pluralidad social (hombres y grupos) en una unidad de poder dotada de determinada estructura y en situación de oponerse a otra del mismo tipo. (...) El proceso integrador se realiza a través de dos vías: a) la racional, consistente en métodos racionalmente calculados o racionalmente utilizados para producir integración, como son la representación jurídico-pública, la organización, el Derecho legal, etc.; y b) la irracional, constituida por formas, métodos e instrumentos predominantemente derivados de fuentes irracionales, tales como las emociones, sentimientos, resentimientos e impulsos capaces de provocar, de fortalecer o de actualizar el proceso integrador, o, eventualmente, de tener los mismos efectos en sentido desintegrador, si se trata de una unidad en curso de escisión. A esta vía irracional de integración pertenecen, entre otros, los símbolos, los mitos y el caudillaje, los cuales, sin embargo, aun derivando de fuentes irracionales, pueden ser racionalmente utilizados y manipulados».

31 Vid. ALDECOA LUZARRAGA, F., y GUINEA LORENTE, M.: «El rescate sustancial de la Constitución Europea a través del Tratado de Lisboa: la salida del laberinto", Documento de Trabajo/Working Paper n. 9, 2008, Real Instituto Elcano [www.realinstitutoelcano.org].

32 Concretamente, según el artículo I-8 (Símbolos de la Unión), del Tratado constitucional de 2004, la divisa de la Unión («Unida en la diversidad») constituía uno de sus símbolos, junto a estos otros: «La bandera de la Unión representa un círculo de doce estrellas doradas sobre fondo azul. El himno de la Unión se toma del 'Himno a la Alegría' de la Novena Sinfonía de Ludwig van Beethoven. (...) La moneda de la Unión es el euro. El Día de Europa se celebra el 9 de mayo en toda la Unión».

33 GARCÍA PELAYO, M.: Mitos y símbolos políticos, op. cit., p. 1019: «La lucha ideológica entre el cristianismo y el Imperio se realizó en su parte principal a través de la literatura simbólica, de la que es ejemplo relevante el Apocalipsis de San Juan». 
ra europea ${ }^{34}$. Todo lo cual, por último, conduce inexorablemente a entender por qué no ha fraguado por el momento un sentimiento constitucional europeo en la ciudadanía ${ }^{35}$, o una conciencia europea en nuestros líderes europeos (que carecen de tal liderazgo) ${ }^{36}$; elementos, ambos, que no son irrelevantes para la emergencia del ius commune europeo y, más aún, para la formación del Derecho constitucional común europeo.

\section{REFLEXIÓN FINAL: SU LEGADO AL DERECHO CONSTITUCIONAL COMÚN EUROPEO}

La expresión «Derecho constitucional común europeo» nos da pie para introducir una reflexión final sobre la contribución del Profesor García Pelayo a la

${ }^{34}$ La bandera con círculo de doce estrellas doradas sobre fondo azul fue adoptada como emblema oficial en el Consejo de Europa en 1955, y en 1985 por la Unión Europea. Sin embargo, en las webs respectivas del Consejo de Europa (www.coe.int) y de la Unión (http://www.europa.eu. int/abc/symbols/emblem/index_es.htm) se explica dicho símbolo con diversa extensión y orientación, siendo por ejemplo más escueta la presentación de la Unión, que a la vez excluye cualquier mención a elementos de influencia religiosa.

35 Como acertadamente critica BAR CENDÓN, A.: «Europa», Las Provincias, 9 de mayo de 2009, p. 27: «el problema que nadie preveía y que ni siquiera los más catastrofistas anunciaban, es el que se ha producido y es el que puede tener — está teniendo ya — más graves consecuencias y de mayor alcance para Europa. Me refiero, lisa y llanamente, a la pérdida de valor del 'europeísmo'. El europeísmo entendido en este sentido como el sentimiento de pertenencia a un colectivo social y político — cuya identidad se percibe en términos sociales y políticos- y la defensa del mismo frente a quienes lo niegan o menosprecian: frente al 'euroescepticismo'».

36 Sobre esta crítica, puede leerse la reciente contribución de TAJADURA TEJADA, J.: «El futuro de Europa», en El Correo Digital, 21 de mayo de 2009 [http://www.elcorreodigital.com/ vizcaya/prensa/20090521/opinion/futuro-europa-20090521.html]. El Profesor Tajadura critica que las elecciones europeas no sean aprovechadas (por unos líderes demasiado apegados a la realidad estatal) como ocasión privilegiada para explicar a la ciudadanía de la Unión hacia dónde nos dirigimos en una empresa común (que tiene en la actualidad como marco de referencia el Tratado de Lisboa) sobre la que se cierne igualmente la crisis: «La crisis económica que padecemos ha puesto de manifiesto las insuficiencias del marco europeo actual. Es preciso aprovechar esta oportunidad para dar un impulso federal a la Unión. Ello sólo será posible creando una Europa a varias velocidades o de círculos concéntricos, en la que los países más reacios a la integración no puedan impedir avanzar a los que quieran hacerlo. ¿Cuál es la posición de los diferentes partidos al respecto? ¿Cuál es su plan B, para el supuesto de que los irlandeses, en un nuevo gesto de egoísmo y falta de solidaridad, volvieran a decir 'no' al Tratado? De la respuesta que se dé a estos y a otros interrogantes depende el futuro de Europa. Los ciudadanos tenemos derecho a saber qué piensan de todo ello los candidatos que solicitan nuestro voto. Y en función de esas respuestas deberíamos decidir en qué sentido ejercer nuestro derecho de sufragio. El 7 de junio, el futuro de Europa está en nuestras manos». 
emergencia del ius commune referente a los dos foros continenales por excelencia, el Consejo de Europa y la Unión Europea ${ }^{37}$.

Efectivamente, como se ha indicado más arriba, su paso por el Tribunal Constitucional español marcó una brillante aprehensión del texto más emblemático del Derecho europeo de los derechos humanos en el ordenamiento constitucional español (el Convenio de Roma de 1950), lo cual ni siquiera se puede ver empañado por el desafortunado episodio del "caso Rumasa", tanto más cuanto que: de un lado, la evolución de la jurisprudencia constitucional española no ha mostrado tener tan claro en nuestros días el alcance del mandato interpretativo del artículo 10.2 o el mandato aplicativo del artículo 96.1, ambos de la Carta Magna española de $1978^{38}$; y, de otro lado, el nivel de politización que se reprocha en la actualidad a nuestra jurisdicción constitucional resulta incomparable y peyorativamente superior a la crítica que pudo formularse al Alto Tribunal en su función de «dirección política» durante el período inicial con García Pelayo como magistrado constitucional ${ }^{39}$.

37 HÄBERLE, P.: «Derecho constitucional común europeo», Revista de Estudios Politicos, nº 79, enero-marzo 1993, p. 11: «Todavía no existe tal Derecho constitucional europeo, toda vez que Europa no forma un único Estado constitucional. Ello no obstante, cada vez va surgiendo un conjunto más y más amplio de principios constitucionales particulares que resultan comunes a los diferentes Estados nacionales europeos, tanto si han sido positivados como si no. Tales principios comunes aparecen parcialmente en las constituciones de los Estados nacionales y en el seno del Derecho consuetudinario constitucional de éstos, derivado también en parte del ámbito de validez del Derecho europeo — como el de la Comunidad Europea, el del Tribunal de Derechos Humanos de Estrasburgo, reforzado recientemente por el Consejo de Europa-, y el dimanante de la Conferencia para la Seguridad y la Cooperación en Europa (que, como es sabido, vincula a Europea con el Atlántico)».

${ }_{38}$ Esa falta de discernimiento se aprecia, a título de ejemplo, en la STC 236/2007, de 7 de noviembre, en cuyo FJ 11 el Tribunal Constitucional se muestra más proclive a la concurrencia que a la complementariedad, cuando afirma que «este derecho a la reagrupación familiar, sin embargo, no forma parte del contenido del derecho consagrado en el artículo $18 \mathrm{CE}$, que regula la intimidad familiar como una dimensión adicional de la intimidad personal, y así lo ha reconocido nuestra jurisprudencia. (...). La jurisprudencia del TEDH, en contraste con la de este Tribunal, (...)».

39 A tal efecto, mantuvo el Maestro GARCÍA PELAYO, M.: «El 'status' del Tribunal Constitucional», en sus Obras Completas, tomo III, Madrid, CEC, 1991, p. 2907: «el Tribunal Constitucional incide en la dirección política del Estado, ya que su función es interpretar y aplicar con carácter supremo el Derecho constitucional, es decir, un Derecho de contenido político al menos en el sentido de que establece los principios configuradores de la unidad política nacional, normativiza los valores en que ésta se sustenta, establece los límites y directrices para la acción estatal y, a través de la institución de órganos, de la determinación de sus competencias y del sistema de relaciones entre ellos, regula la estructura y las funciones políticas del Estado. Un Derecho que establece las pautas normativas firmes dentro de las cuales acontece el dinamismo político, que crea el marco normativo fundamental de la acción política del Estado y que establece vías de trans- 
Es cierto que el marco constitucional trazado por los mencionados artículos 10.2 y 96.1 se ha enfrentado a un desarrollo exponencial de la jurisprudencia del Tribunal Europeo de Derechos Humanos, lo cual podría justificar una cierta reflexión en clave de «reserva constitucional» en la asunción del canon europeo en sede de justicia constitucional, así como un cierto eclipsamiento de los Tribunales Constitucionales nacionales ante la instancia con sede en Estrasburgo que parece erigirse en una especie de «Tribunal Constitucional Europeo». Ahora bien, mientras actualmente parece darse la impresión negativa de una potencial conflictividad entre la jurisdicción/jurisprudencia constitucional y la jurisdicción/jurisprudencia europea, en la primera época del Tribunal Constitucional español se ponía aparentemente más el acento en la interacción mutua ${ }^{40}$, y las reuniones de Presidentes de Tribunales Constitucionales europeos se mostraban como una ocasión propicia para alentar ese enfoque positivo ${ }^{41}$.

formación de los poderes sociales en poderes estatales y de los valores políticos en normas vinculatorias o en directivas de la acción estatal».

40 En este ámbito, véase el informe titulado «Protection constitutionnelle et protection internationale des droits de l'homme: concurrence ou complémentarité?», Rapport présenté par la délégation française à la IXe conférence des Cours constitutionnelles européennes (Paris, 10-13 mai 1993), Revue française de Droit administratif, 9 (5), septiembre-octubre 1993, pp. 849-869. Léase asimismo EISSEN, M.A.: "Cours constitutionnelles nationales et Cour européenne des droits de l'homme: leur influence mutuelle», Revue Trimestrielle des Droits de l'homme, no 6, abril 1991, p. 171: quien fuera Secretario del Tribunal Europeo se refirió a la influencia recíproca de los tribunales constitucionales y del Tribunal Europeo por referencia a España: «he aquí una ilustración reciente. El 16 de diciembre de 1987 (STC 199/1987) el Pleno del Tribunal Constitucional de España declaró inconstitucional el artículo 13 de una ley orgánica de 26 de diciembre contra las actuaciones de bandas armadas y elementos terroristas. Dicho artículo autorizaba a prolongar de setenta y dos horas a diez días, mediante decisión judicial, la duración máxima (setenta y dos horas) de la detención preventiva. El Tribunal Constitucional, por unanimidad, lo estimó contrario al artículo 5.3 CEDH, que obliga a llevar inmediatamente ("aussitôt»/"promptly») ante un juez o un magistrado habilitado por ley para ejercer funciones judiciales, a un individuo que se halle en detención preventiva».

${ }^{41}$ Buen botón de muestra lo ofrecen las «Palabras en la sesión de apertura de la VI Conferencia de Tribunales Constitucionales Europeos» pronunciadas por Manuel García Pelayo (quien presidió dicha Conferencia, celebrada en Madrid, los días 22, 23 y 24 de octubre de 1984). En tal discurso (en sus Obras Completas, tomo III, pp. 3229-3231) quedó claro el talante europeísta de García Pelayo: "Como pertenecientes al círculo común de la cultura europea, los países aquí presentados participamos en una misma imagen política y jurídica del mundo y de la vida, aunque sean distintas la formas específicas en que tal imagen se configura en cada uno de nosotros. Con ello se manifiesta, en nuestro campo, esa presencia simultánea de unidad y de diversidad que parece ser esencial al modo de existir europeo, si bien en el tiempo presente se acrecen en conjunto los factores de integración, sin perjuicio de la singularidad de cada uno de los países que componen el cuerpo histórico de Europa. Bajo estos supuestos, parece clara la importancia que tiene el 
Sin desmerecer la altura de los sucesivos Presidentes y Presidentas, y en general de los magistados y magistradas del Tribunal Constitucional español, es indudable que nuestro supremo intérprete de la Constitución en el ámbito interno no goza en los últimos tiempos del prestigio de antaño con García Pelayo a la cabeza. Sin, por lo demás, entrar a ponderar el modo en que se está desenvolviendo en sede de jurisdicción constitucional la interpretación del sistema de fuentes nacionales (sobre todo, en términos de conflictividad provocada por el desarrollo y profundización en nuestro Estado autonómico), se impone una reflexión más seria sobre la aplicación del Derecho europeo en el ordenamiento español $^{42}$.

Por supuesto, no se puede hacer recaer exclusivamente el peso de esa reflexión en torno al sistema jurídico sobre el Tribunal Constitucional —por más que él pronuncie la última palabra-. Los universitarios (hablo, sobre todo, por los constitucionalistas) tenemos prima facie un deber de implicación en semejante tarea ${ }^{43}$, alimentando la discusión sobre la adecuada sinergia entre las fuentes nacionales y las fuentes europeas y, por ende, ofreciendo herramientas científicas útiles para quienes tienen la difícil tarea de decidir. De otro modo, parece

intercambio de ideas y experiencias entre las jurisdicciones constitucionales europeas, pues si bien es obvio que las decisiones de cada una de ellas sólo tienen vigencia en sus respectivos ámbitos, no es menos cierto que de su doctrina pueden extraerse unos preceptos, unos métodos y unas modalidades de interpretación que trascienden a las circunstancias concretas de cada uno, para adquirir, en muchos casos, una validez generalizada. Común es, en buena parte, nuestra problemática; comunes son, en lo esencial, nuestros valores, y comunes son, en lineas generales, nuestras funciones, que se sintetizan en la tarea de afirmar la primacía de la Constitución sobre el orden jurídico y político como condición tanto para asegurar el funcionamiento racional y, por ende, eficaz del Estado como para garantizar el respeto de los valores políticos que lo inspiran y legitiman. Partiendo de esta unidad en los puntos nucleares, parece claro que la confrontación de experiencias de cada Tribunal puede y debe enriquecer la doctrina común y contribuir a la formación de un Ius Publicum Europaeum, lo que, sin duda, constituirá una aportación de primer rango para la integración de Europa».

42 De obligada referencia en esta materia, con un análisis comparado, es la obra de VIDAL PRADO, C.: El impacto del nuevo Derecho europeo en los Tribunales constitucionales, Madrid, Colex, 2004. Interés presenta, asimismo, el Informe del Consejo de Estado sobre la inserción del Derecho europeo en el ordenamiento español (381 pp.) de 14 de febrero de 2008 [www.consejo-estado.es/pdf/Europa.pdf].

${ }^{43}$ Así lo entendió García Pelayo, como ha advertido SORIANO, G.: «Manuel García-Pelayo en el desarrollo del Derecho constitucional del siglo XX», Cuestiones Constitucionales, no 13, julio-diciembre 2005 [http://www.ejournal.unam.mx/cuc/cconst13/CUC1306.pdf], p. 220: al aludir al clásico Derecho constitucional comparado, recuerda la autora cómo la segunda edición (de 1951) incorporó como novedad el capítulo VII (»Uniones de Estados y Estado federal»), tratando «allí de modo magistral temas que parecían materia casi exclusiva del Derecho internacional», pero que «se trata de la regulación de situaciones que condicionan en diferente medida la estructura constitucional». 
que el efímero proceso de «constitucionalización» de Europa (con el pretexto, especialmente, del debate acerca de las Convenciones que elaboraron la Carta de los derechos fundamentales y el Tratado constitucional) no habría pasado de ser una mera y pasajera operación de «marketing constitucional $»^{44}$ sin ulterior interés para los constitucionalistas. En otras palabras: no es preciso que el Tratado de Lisboa se adjetive de «constitucional» (y, más aún, a la luz de la alergia que dicho Tratado ha mostrado con respecto a cualquier manifestación explícita de "constitucionalización») para que seamos conscientes de nuestra responsabilidad, pues a los constitucionalistas se nos tiene en cuenta en la formación del ius commune europeo y, como parte de él, al forjado en la Europa de los derechos fundamentales $^{45}$.

Quizá el diseño del sistema universitario español (en el que han tenido una incidencia mayor las lógicas aspiraciones de promoción del personal docente e investigador que la utilidad del estudio para la sociedad del conocimiento) haya generado un exceso de publicaciones en torno al mencionado proceso de constitucionalización de Europa, es decir, una inflación de investigaciones que ha generado cierta dispersión necesitada de una cierta ordenación de ideas en torno a las líneas maestras del Derecho constitucional europeo. ¡Cuán interesante habría sido conocer las ideas del Profesor García Pelayo acerca del proceso de constitucionalización de Europa! Seguramente nos habríamos centrado más en la sustancia y nociones básicas (en el sustrato) del Derecho constitucional europeo que en cuestiones terminológicas (si el Tratado constitucional era una Constitución o no, etc.) que, sobre ser importantes, han desviado nuestra atención ${ }^{46}$. Esa clarividencia de ideas es la que, a título de ejemplo, llamó la atención

${ }^{44}$ Crítica efectuada por ALEGRE MARTÍNEZ, M.A., y JIMENA QUESADA, L.: Fundamentos constitucionales de la Unión Europea, Madrid, Biblioteca Nueva, 2006, p. 274. En este sentido, la inclusión de «cláusulas europeas» en los textos constitucionales de los Estados miembros ha sido sugerida como un instrumento adecuado para la constitucionalización en Europa: así, ASTOLA MADARIAGA, J.: «De la legitimidad democrática de la Unión Europea y de la legitimación democrática de sus decisiones: una reflexión sobre el proyecto de Constitución Europea», Teoría y Realidad Constitucional, no 15, 2004, p. 234.

45 Baste ilustrar dicha observación con la circunstancia actual de que Luis López Guerra sea el magistrado español del Tribunal Europeo de Derechos Humanos (para el período 2008-2013), y que a mí personalmente me cumpla el honor de ser uno de los quince miembros del Comité Europeo de Derechos Sociales (para el mandato 2009-2014). Es decir, se nos ha confiado una alta responsabilidad en el seno de los órganos de garantía de los dos tratados básicos del Consejo de Europa, el Convenio Europeo de Derechos Humanos y la Carta Social Europea, respectivamente.

46 Sobre la necesidad de ser conscientes del aparato conceptual del Derecho constitucional ya alertó GARCÍA PELAYO, M.: Derecho constitucional comparado, op. cit., pp. 255-256: «pocas esferas jurídicas aparecen tan manifiestamente impregnadas de criterios axiológicos como lo fueron 
de García Pelayo en la redacción de su «Epílogo» a la teoría constitucional de Carl Schmitt ${ }^{47}$.

Para concluir: en su «Autobiografía intelectual» recalca García Pelayo, con motivo de su llamamiento por la Universidad Central de Venezuela para organizar el Instituo de Estudios Políticos (que dirigió desde 1958 hasta su jubilación en 1979), cómo dicho Instituto inició su andadura «bajo el influjo de las concepciones europeas» y evolucionó a través de la "posición hegemónica [de] las concepciones norteamericanas ${ }^{48}$. Con semejante orientación, creo que reviste interés la tendencia a la convergencia entre los sistemas de «civil law» y de "common law» que se percibe en nociones básicas como la idea del «Estado de Derecho $"{ }^{49}$, una tendencia que sin duda ha permitido apuntalar y debe continuar apuntalando los cimientos de la construcción del ius commune europeo ${ }^{50}$.

las normas jurídicas constitucionales para la conciencia política dominante del siglo XIX (aunque no siempre para la jurídica: positivismo) (...). Mas con ello nacía la necesidad no sólo de establecer un sistema de conceptos que convirtiera en unidad la pluralidad normativa, sino también la de descubrir el genuino sentido de los preceptos normativos. Esto tuvo una importancia fundamental para la concepción del Derecho constitucional como una ciencia estimativa que no se limitaba a explicar unas relaciones, sino que tenía también que captar el espíritu de las instituciones, proporcionando criterios de valor para la conducción de la actividad estatal».

47 GARCÍA PELAYO, M.: «Epílogo» a Teoría de la Constitución de Carl SCHMITT, Madrid, Alianza Universitaria Textos, 1982 (1ª reimpr. de 1992), p. 374: al referirse a la obra de Schmitt, se detiene García Pelayo «en la formulación — por vez primera, que yo sepa— de una Teoría de la Constitución como disciplina autónoma, en la teoría de la garantía institucional, en la precisión de la doctrina de la representación, etc., debidas al propio Carl Schmitt. Se trata, como antes decimos, de ideas, formulaciones y conceptos que hoy forman parte, de uno u otro modo, de la praxis y de la teoría del patrimonio constitucional común a los pueblos occidentales europeos".

48 GARCÍA PELAYO, M: "Autobiografía intelectual», op. cit., p. 13.

49 Cfr. SUMMERS, R.S.: «A Formal Theory of the Rule of Law», Ratio Juris, Vol. 6, No. 2, July 1993; el autor, con relación a las ventajas de la teoría sustancial del «rule of law» señala que «ésta se caracteriza principalmente por el mayor contenido sustantivo que incorpora. Así, incorpora, en diferentes grados, algunas de las siguientes medidas: normas que garantizan un mínimo de bienestar social, por ejemplo, el 'welfare state', normas que aseguran determinadas variables de la economía de mercado, normas que protegen al menos algunos derechos humanos básicos, y normas que institucionalizan la gobernabilidad democrática» (p. 135). Lo anterior no resta importancia — según el autor- a las aportaciones y virtudes de una teoría formal del «rule of law», que cifra en las siguientes: valores como la predictibilidad; la mayor consistencia y congruencia en la metodología interpretativa de las normas, al existir reglas más precisas para emitir un fallo, mejor delimitación del poder del juez para apartarse del precedente, e incluso mayor independencia judicial; minoración de disputas; y legitimidad (pp. 136-141).

50 El propio García Pelayo, en fin, se mostraba convencido de la virtualidad de dicha tendencia convergente, cuando nos relata en su "Autobiografía intelectual» (op. cit., p. 15) que "creía en la posibilidad y, más aún, en la necesidad de la construcción de una teoría general de la po- 
Title:

«PROFESSOR GARCÍA PELAYO AND THE EMERGENCE OF THE EUROPEAN JUS COMMUNE».

\section{Summary:}

I. INTRODUCTORY ISSUES: THE EUROPEAN VOCATION OF GARCÍA PELAYO. II. ON HIS INTEREST FOR THE EUROPE OF HUMAN RIGHTS. III. HIS APPROACH TO THE EUROPE OF INSTITUTIONS. IV. CONCLUDING THOUGHTS: HIS LEGACY TO THE COMMON EUROPEAN CONSTITUTIONAL LAW.

\section{Resumen:}

El legado científico del Profesor García Pelayo sigue constituyendo uno de las más preciosas fuentes para la comprensión del constitucionalismo europeo de nuestros días. En efecto, la aproximación al pensamiento constitucional de García Pelayo nos brinda la oportunidad de reflexionar de manera más sólida y profunda sobre el proceso de constitucionalización de Europa. El bagaje constitucional de García Pelayo evoca que Europa (la de los derechos humanos y la de las instituciones) se construye sobre la base de valores constitucionales compartidos.

\section{Abstract:}

The Scientific Legacy of Professor García Pelayo remains one of the most valuable sources for the understanding of the current European constitutionalism. In effect, the approach to the Constitutional Thinking of García Pelayo offers us the opportunity to reflect in a more solid or profound way on the process of constitutionalisation of Europe. The constitutional background of García Pelayo suggests that Europe (both of human rights and institutions) is built on the basis of common constitutional values.

Palabras clave:

Principios constitucionales comunes - Sentimiento constitucional europeo - Interacción entre Jurisdicciones constitucionales y europeas Apertura al constitucionalismo europeo.

lítica basa en un substratum histórico lo bastante amplio para que sus formulaciones no se limitaran solamente al mundo occidental y a la época presente». 


\section{Keywords:}

Common constitutional principles - European constitutional feeling - Interaction between Constitutional and European Jurisdictions Opening to European Constitutionalism 